\title{
Obligations and Prohibitions in Talmudic Deontic Logic
}

\author{
Michael Abraham ${ }^{1}$, Dov M. Gabbay ${ }^{1,2,3}$, and Uri Schild ${ }^{1}$ \\ 1 Bar Ilan University, Israel \\ 2 King's College London \\ ${ }^{3}$ University of Luxembourg
}

\begin{abstract}
This paper examines the deontic logic of the Talmud. We shall find, by looking at examples, that at first approximation we need deontic logic with several connectives:

$O_{T} A \quad$ Talmudic obligation

$F_{T} A \quad$ Talmudic prohibition

$F_{D} A \quad$ Standard deontic prohibition

$O_{D} A \quad$ Standard deontic obligation.

In classical logic one would have expected that deontic obligation $O_{D}$ is definable by

- $O_{D} A \equiv F_{D} \neg A$

and that $O_{T}$ and $F_{T}$ are connected by

- $O_{T} A \equiv F_{T} \neg A$

This is not the case in the Talmud for the $T$ (Talmudic) operators, though it does hold for the $D$ operators. We must change our underlying logic. We have to regard $\left\{O_{T}, F_{T}\right\}$ and $\left\{O_{D}, F_{D}\right\}$ as two sets of operators, where $O_{T}$ and $F_{T}$ are independent of one another and where we have some connections between the two sets.

We shall list the types of obligation patterns appearing in the Talmud and compare Talmudic Logic with modern deontic logic.
\end{abstract}

\section{Motivating Talmudic Deontic Logic TDL}

This paper is written for researchers in Deontic Logic and Contrary to Duties who would like to know how things stand in Talmudic logic. To set the scene for our paper, we give some short background material.

The simplest and historically first logical system offered for dealing with obligation is Standard Deontic Logic SDL, which is the modal logic KD for an operator $O_{D} A$ reading ' $A$ is obligatory'. The semantics for $O$ are models of the form $(S, R, h)$, where $R \subseteq S^{2}, h$ is the assignment to the atoms, assigining each atom $q$ of the language a subset $h(q) \subseteq S$, and $R$ satisfies $\forall x \exists y x R y$.

This system was too simple and researchers in the community offered systems with dyadic modalities $O_{D}(A / C)$, reading ' $A$ is obligatory in the context $C$ '. This was a response to contrary to duty examples which could not be properly modelled by the unary $O_{D}$.

One such famous example is the Chisholm set 1

${ }^{1}$ The translation of (1)-(4) must give four consistent and logically independent sentences adequately representing the linguistic text.

G. Governatori and G. Sartor (Eds.): DEON 2010, LNAI 6181, pp. 166-178, 2010.
(c) Springer-Verlag Berlin Heidelberg 2010 
1. It ought to be that a certain man goes to assist his neighbour.

2. It ought to be that if he does go he tells him he is coming.

3. If he does not go he ought not to tell him he is coming.

4. He does not go.

If we use $H$ for 'help' and $T$ for 'tell', we have two options to formalise this set, either with $O_{D} X$ (unary) or with $O_{D}(X / Y)$ dyadic.

\begin{tabular}{l|c|c} 
clause & monadic & dyadic \\
\hline 1. & $O_{D} H$ & $O_{D}(H / \top)$ \\
\hline 2. & $H \rightarrow O_{D} T$ & $H \rightarrow O_{D}(T / H)$ \\
\hline 3. & $\neg H \rightarrow O_{D} \neg T$ & $\neg H \rightarrow O_{D}(\neg T / \neg H)$ \\
\hline 4. & $\neg H$ & $\neg H$ \\
\hline
\end{tabular}

The following sums up the spirit of the research of the deontic community.

1. Find reasonable logical systems involving various monadic or dyadic modal operators with possible world or preferential semantics in which various linguistic deontic sets can be consistently and adequately formalised.

2. Emphasise the CTD examples and calibrate your logics to deal with various problems associated with them.

The community lays stress on the theory of CTDs as distinctly characteristic to deontic logic, which sets it apart from being a secondary applied branch of modal logic. It is also felt that the essence of the deontic area is the possibility of violations and hence the core of deontic logic as a discipline distinct from modal logic is its theory of CTD.

For our purpose a contrary to duty system is a set $\Delta$ of formulas of the form $\left\{\delta_{1}, \ldots, \delta_{n}\right\}$ where

$$
\delta_{i}=O\left(X_{i} / Y_{1} \wedge \ldots \wedge Y_{k(i)}\right)
$$

Given a consistent set

$$
\theta=\left(E_{1}, \ldots, E_{k}\right)
$$

we consider the set

$$
\Delta_{\theta}=\left\{X_{i} \mid \delta_{i}\left(X_{i} / Y_{1} \wedge \ldots Y_{k(i)}\right) \in \Delta \text { and } \theta \vdash Y_{j}, j=1, \ldots, k(i)\right\}
$$

$\Delta_{\theta}$ is the set of obligations triggered by the context $\theta . \Delta_{\theta}$ may be an inconsistent set and part of any CTD logic is to "recommend" a consistent subset $\Delta_{\theta}^{\text {con }} \subseteq \Delta_{\theta}$. The "logic" has to deal coherently and in a compatible manner with common sense with the relationship between pairs of the form $\left(\theta, \Delta_{\theta}^{\text {con }}\right)$ and $\left(\theta^{\prime}, \Delta_{\theta^{\prime}}^{\text {con }}\right)$. As far as we know, no comprehensive theory of this form exists. See references [1|2|3|4].

In contrast with the above, The Talmud, being a religious code of law, given to us by God in the Bible, has two types of deontic rules: action obligations and action prohibitions. Both types represent the will of God for us to obey. This is why at a first logical approximation we need two independent deontic operations $O_{T}$ and $F_{T}$ (the subscript ' $T$ ' stands for 'Talmudic') as well as the standard deontic prohibition $F_{D}$.

There are some points we need to make clear. The variables $X$ that go into the connectives $O_{T} X, F_{T} X, O_{D} X$ and $F_{D} X$ denote actions like work, lift, steal, wear Tefilin (Tefilin 
is something men wear when they offer morning prayers during week days), etc. and not lack of action like resting, not stealing, etc. When we negate them and write $\neg X$, we denote lack of action.

One might think that we can model obligations and prohibitions using only one deontic operator $O$, letting $O X$ represent obligations and $O \neg X$ represent prohibitions. However this is not correct. Our obligations and prohibitions can apply either to $X$ or to $\neg X$. See examples below under the heading “Type 3: Strong obligation/prohibition". So $O_{T} X$ is a Biblical obligation to take action $X . O_{T} \neg X$ is a Biblical obligation not to take action $X . F_{T} X$ is a Biblical prohibition to take action $X$ and $F_{T} \neg X$ is a Biblical prohibition not to take action $X$ (i.e. we are prohibited from choosing not to take action $X$ ). So $O_{T} X$ is not equivalent to $F_{T} \neg X$. So if $X=$ wear Tefilin, then having an obligation to wear it is not the same as being prohibited from not wearing it. So in some cases God requires us to obey both i.e. $O_{T} X \wedge F_{T} \neg X$. The reader should recall intuitionistic logic where $\neg \neg A$ is weaker than $A$, so the negation used in these commands have intuitionistic flavour. (In fact, the Talmudic system was originally modelled in intuitionistic modal logic but we decided to keep the logic classical, pending further modelling investigations).

If we look at this situation as logicians, we can say we have here three pairs of modal operators, each pair being of the form (Necessity of the form $N X$ and Possibility of the form $P X=\neg N \neg X)$. The pairs are $\left(N_{i}, P_{i}\right), i=1,2,3$ as follows.

1. $O_{T} X$ and $\neg O_{T} \neg X$

2. $F_{T} \neg X$ and $\neg F_{T} X$

3. $O_{D} X$ and $\neg F_{D} X=\neg O_{D} \neg X$.

Since the Talmud gives no connections between $O_{T}$ and $F_{T}$, we have to represent them as two pairs $\left\{N_{1} X=O_{T} X, P_{1} X=\neg O_{T} \neg X\right\}$, and $\left\{N_{2} X=F_{T} \neg X, P_{2} X=\neg F_{T} X\right\}$.

This can be made clearer when we consider the operational differences between $O_{T} A$ and $F_{T} A$ and $F_{D} A$.

1. If you obey $O_{T} A$ then God rewards you. You are also obliged to spend $20 \%$ of your income to enable yourself to fulfil your obligation.

2. If you violate $F_{T} A$, and actually do the forbidden $A$, then you will be punished (by God and or by law/society). Also you should devote $100 \%$ of your income to enable yourself to avoid doing $A$.

Therefore for the same $X$, if the Bible says $O_{T} X$ then 1. applies and if the Bible says $F_{T} \neg X$, which in practice means the same to us, then 2 . applies.

$F_{D} A$ says it is forbidden to have $A$ for whatever reason, without going into the fine tuning of why this is so. It may arise from a Biblical $O_{T} \neg A$, or from $F_{T} A$ or from some related $F_{T} Y$ or whatever.

For example, in Type 1A: Obligation with deontic prohibition below we have $O_{T}$ (wear Tefilin during prayer). From this it follows that $F_{D}$ (pray without wearing Tefilin).

However we do not have a direct Biblical prohibition $F_{T}$ (pray without Tefilin), and therefore if one actually does pray without wearing Tefilin, there is no punishment from God.

Note that we do not necessarily have any connections like

$$
O_{T} X \rightarrow \neg F_{D} X
$$


and

$$
F_{T} X \rightarrow F_{D} X
$$

If we had them we could have derived

$$
O_{T} X \rightarrow \neg F_{T} X
$$

However we know that there is no such axiomatic connection in Talmudic logic. The reason for that is as we mentioned earlier, $O_{T}$ and $F_{T}$ are in general generic and possibly conflicting, and it is the Rabbis who decide day-to-day how to apply the commands in any given situation.

It is possible also to have both $F_{T} X$ and $O_{T} X$ for the same $X$ (even though on the surface this seems contradictory) because $X$ may be a generic kind of predicate and it is expected that the Rabbis will decide for each situation $\mathbf{s}$ which obligation/prohibition applies. In fact, in many cases the Bible gives recipes (more precisely there are indirect hints in the Biblical text but the main derivation of recipes is done in the Talmud) for making such decisions. In our model these recipes are part of the (nonmonotonic) mechanisms of conflict resolution.

It is the job of the Rabbis to make decisions (according to some principles) how to resolve conflicts between obligations and prohibitions when applied to any particular situations.

The emphasis of Talmudic Deontic Logic is therefore on

1. Deciding what are the Biblical $O_{T} X, F_{T} X$. (This has been done: there are 613 master ones, though opinions differ as to which are included among these 613.)

2. Deciding which Biblical $O_{T} X, F_{T} Y$ apply to any new arising situation $\mathbf{s}$.

3. Resolving possible conflicts between applicable rules for any $\mathbf{s}$.

The role of CTDs is not central to the Talmudic system, nor is the theoretical maintainance of consistency. The Biblical rules are known to cause conflict and established procedures and recommendations and institutions for conflict resolution and practical day-to-day decision making are also given by the Bible.

Note that there are differences between this decision making process and precedents and legislation in law. We shall not go into that here.

The following table, Table 1 compares Talmudic Deontic ideas with their modern counterparts.

To compare CTDs, let us look at some examples from the Bible 2

\section{Example 1 (Chisholm variant 1)}

1. You ought to have a ceremonial meal during the Passover festival.

2. If you have your meal you ought to say prayer (blessing, grace).

3. If you do not have the meal you ought not say the prayer (blessing).

4. You do not have the meal.

(1)-(3) are Biblical obligations. We formalise them using dyadic modalities.

1. $O_{T} M\left(\right.$ or $\left.O_{T}(M / \top)\right)$

2. $M \rightarrow O_{T} B\left(\right.$ or $\left.M \rightarrow O_{T}(B / M)\right)$

\footnotetext{
${ }^{2}$ The Talmud interprets the Bible. So when we say Talmudic logic, this includes Biblical logic.
} 
Table 1.

\begin{tabular}{|c|c|c|c|}
\hline & $\mid \begin{array}{ll}\text { Deontic } & \text { com- } \\
\text { munity } & \end{array}$ & Talmud & Comments \\
\hline $\begin{array}{l}\text { Sources of } \\
\text { obligations and } \\
\text { prohibitions }\end{array}$ & $\begin{array}{l}\text { common sense, } \\
\text { law, moral code }\end{array}$ & Bible/God & $\begin{array}{l}\text { It took hundreds of years to } \\
\text { study and summarise the Tal- } \\
\text { mudic obligations and prohibi- } \\
\text { tions. } 613 \text { major types were fi- } \\
\text { nally agreed upon by the end } \\
\text { of the middle ages, though as } \\
\text { we already mentioned, opinions } \\
\text { differ as to which are included } \\
\text { among these } 613 \text {. }\end{array}$ \\
\hline Formalisation & \begin{tabular}{|lr} 
Monadic & or \\
dyadic & opera- \\
tors, & preference \\
or & possible \\
world & models.
\end{tabular} & $\begin{array}{l}\text { Two levels } \\
O_{T}, F_{T}, \quad \text { and } \\
O_{D}, F_{D} \text { The } \\
\text { handling meta- } \\
\text { logic is some } \\
\text { kind of time } \\
\text { action logic }\end{array}$ & $\begin{array}{l}\text { Modern deontic logic is a well } \\
\text { developed area. This paper is a } \\
\text { first attempt in formalising Tal- } \\
\text { mudic deontic logic }\end{array}$ \\
\hline Status of CTD & central & marginal & $\begin{array}{l}\text { The Talmud views CTD as just } \\
\text { more conditional obligations }\end{array}$ \\
\hline $\begin{array}{l}\text { Conflict resolu- } \\
\text { tion }\end{array}$ & $\begin{array}{l}\text { Recognised but } \\
\text { not central yet. } \\
\text { The community } \\
\text { is beginning } \\
\text { to address the } \\
\text { problem. }\end{array}$ & central & $\begin{array}{l}\text { Deontic community recognises } \\
\text { the problem of inherited con- } \\
\text { flicting CTDs. They emphasise } \\
\text { consistency. Talmud expects in- } \\
\text { consistency even of original } \\
\text { obligations. Emphasises meth- } \\
\text { ods of resolving conflicts. }\end{array}$ \\
\hline $\begin{array}{l}\text { Status of viola- } \\
\text { tions }\end{array}$ & 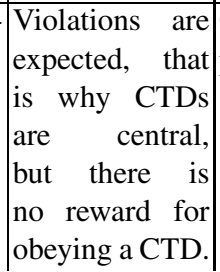 & $\begin{array}{l}\text { Obeyance is ex- } \\
\text { pected }\end{array}$ & $\begin{array}{l}\text { Talmud emphasises punishment } \\
\text { for violations and reward for } \\
\text { obeyance. }\end{array}$ \\
\hline
\end{tabular}

3. $\neg M \rightarrow F_{T}(B / \neg M)$

4. $\neg M$.

Note that the Bible is explicit about $F_{T}(B / \neg M)$ and does not say $O_{T}(\neg B / \neg M)$. The Bible says generally "Do not use the name of God in vain", which applies to this case as well!

\section{Exodus 20:7}

You shall not take the name of the LORD your God in vain, for the LORD will not leave him unpunished who takes His name in vain.

We do $n o t$ have the equivalence $O_{T}(\neg x / z) \equiv F_{T}(x / z)$. 
Compare the above with the following.

\section{Example 2 (Chisholm variant 2)}

1. We are obliged to eat meat from sheep at passover.

Exodus 12:21

Then Moses called for all the elders of Israel and said to them, Go and take for yourselves lambs according to your families, and slay the Passover lamb.

2. If we eat meat we should slaughter the sheep humanely.

3. If we do not eat meat we should not slaughter the sheep.

4. We do not eat meat.

The translation is as follows ( $E$ is Eat and $H$ is sheep):

1. $O_{T}(E / T)$.

2. $E \rightarrow O_{T}(H / E)$.

3. $\neg E \rightarrow F_{D}(H / \neg E)$

4. $\neg E$

Note that in (3) we used $F_{D}$ because the Bible is not explicitly prohibiting killing animals for no reason but the prohibition follows from Rabbinical practical rulings.

Thus the reward from God for obeyance is different in the two cases. Note that it is easier to avoid the Chisholm paradox for examples 1.1 and 1.2 since our logic language is more refined.

The rest of this section will give examples of the major existing types of Talmudic obligations and prohibitions and formalise the examples in terms of $O_{T}, F_{T}$ and $F_{D}$. The reader should note that we may have less or different paradoxes for the Talmudic system, which has more operators and so more fine distinctions can be made. Furthermore if in ordinary deontic logic we allow more operators to stand for strong moral (parallel to Talmudic) obligations and prohibitions, then we might find that some paradoxes disappear. Although we have not given yet to the reader the axiom system and semantics for these operators, we have given enough of their intuitive meaning and this should suffice for our initial formalisation.

Let us now briefly describe the eight types of obligations and prohibitions available in the Talmud.

We shall also give a preliminary intuitive formalisation in terms of $O_{T}, F_{T}$ and $F_{D}$ (note that $O_{D}$ is definable from $F_{D}$, so we do not need it). In the sequel, we distinguish Types $1 \mathrm{~A}, 1 \mathrm{~B}$ and $1 \mathrm{C}$. They all arise from the same Biblical Talmudic obligation $O_{T}$. The differences between them is practical implementations, as summarised in Table 2 .

\section{Type 1A. Obligation with Deontic Prohibition}

As an example, we have to respect and honour our parents (this is one of the Ten Commandments), so we have $O_{T}$ (Respect Parents). If we do not respect our parents, there is a violation. See Table 2 item 1A. The Bible says respect your parents so that you will live long and prosper. It does not threaten punishment if you do not. 
Deuteronomy 20:8

Honor thy father and thy mother, that thy days may be long upon the land which the LORD thy God giveth thee.

Perhaps a modern example will help. We all read some Harry Potter books. The newspapers reported that the author J. K. Rowling gave her father copies of the first edition of her books, signed and dedicated by her. The idea was that he was supposed to keep them. The father needed money and so he sold them. We formalise the intention/convention by $O_{T}$ keep $\wedge F_{D} \neg$ keep.

He is not supposed to sell them because he is expected to keep them.

\section{Type 1B. Weak Obligation}

There is an obligation to live in the land of Israel. The question is whether from this obligation there is a deontic prohibition on living outside Israel. The answer is no, according to a minority opinion. Now if you do not live in Israel, there is no violation. See Table 2, item 1B. This is a unique case where the weak obligation is some sort of recommendation. You get a reward if you do it but there is no violation if you do not do it.

\section{Type 1C. Prohibition Arising from Positive Obligation}

We need to let the land rest every seven years. As part of this the fruits of trees on the seventh year are allowed to be eaten by anyone, not just the owners of the tree, but are not allowed to be sold or traded with. This is to stop the temptation for farmers to work the land and trade the produce.

We write this as

$$
F_{D} \text { (trade fruit of tree) }
$$

We do want you to eat the fruit and not to sell them. We do not require in practice to eat the fruit. The Talmudic $O_{T}$ eat is not enforced. I.e. you have no actual obligation to eat the fruit only not to sell them.

Leviticus 25:1-7

God spoke to Moses at Mount Sinai, telling him to speak to the Israelites and say to them: When you come to the land that I am giving you, the land must be given a rest period, a sabbath to God. For six years you may plant your fields, prune your vineyards, and harvest your crops, but the seventh year is a sabbath of Sabbaths for the land. It is God's sabbath during which you may not plant your fields, nor prune your vineyards. Do not harvest crops that grow on their own and do not gather the grapes on your unpruned vines, since it is a year of rest for the land. [What grows while] the land is resting may be eaten by you, by your male and female slaves, and by the employees and resident hands who live with you. All the crop shall be eaten by the domestic and wild animals that are in your land. 
Leviticus 25:20-22

And if ye shall say: 'What shall we eat the seventh year?' behold, we may not sow nor gather in our increase'; then I will command My blessing upon you in the sixth year, and it shall bring forth produce for the three years. And ye shall sow the eighth year, and eat of the produce, the old store; until the ninth year, until her produce come in, ye shall eat the old store.

To sharpen and clarify the distinctions between Type 1A and Type 1C, note that during Sukkot, the feast of Tabernacles, we must eat our meals inside the Sukkah, a temporary hut you build in your garden. However if you do eat outside the Sukkah, no punishment is due. It is not clear how to formalise it. Opinions differ, it is either of Type 1A or of Type 1C. The book Minhat Hinuch says that if we adopt Type 1A, then if one uses a stolen Sukkah one has not fulfilled his obligation, since he committed a violation in the process, however, if we adopt the view that the Type is $1 \mathrm{C}$, then he has fulfilled his obligation.

Compare with Type 2. For a prohibition of Type 2, of the form $F_{T} X$, if we violate it and do perform $X$ we get punished! We do not get punished if we violate Type $1 \mathrm{~A}$ or Type 1C.

Table 2.

\begin{tabular}{|c|c|c|}
\hline$O_{T} X$ & If you do $X$ & If you do $\neg X$ \\
\hline $\begin{array}{l}\text { Type } 1 \mathrm{~A} \text {, in this } \\
\text { case we also } \\
\text { have } F_{D} \neg X \text { and } \\
\text { consequently } \\
O_{D} X\end{array}$ & $\begin{array}{l}\text { You obeyed the } \\
\text { will of God. } \\
\text { God rewards } \\
\text { you in Heaven }\end{array}$ & $\begin{array}{l}\text { You committed violation. You } \\
\text { will have to face the conse- } \\
\text { quences in Heaven. }\end{array}$ \\
\hline $\begin{array}{l}\text { Type } 1 \mathrm{~B} \text {, in this } \\
\text { case we do not } \\
\text { have } F_{D} \neg X \text {. }\end{array}$ & as above & $\begin{array}{l}\text { The incident is not recorded in } \\
\text { Heaven }\end{array}$ \\
\hline $\begin{array}{l}\text { Type } 1 \mathrm{C} \text {, in this } \\
\text { case we only } \\
\text { have } F_{D} \neg X \\
\text { without having } \\
O_{T} X\end{array}$ & $\begin{array}{l}\text { Your obeyance } \\
\text { is not recorded } \\
\text { in Heaven }\end{array}$ & $\begin{array}{l}\text { You committed violation. You } \\
\text { will have to face the conse- } \\
\text { quences in Heaven. }\end{array}$ \\
\hline Comment & \multicolumn{2}{|c|}{$\begin{array}{l}\text { If you obey } 1 \mathrm{~A} \text { by committing a violation which } \\
\text { harms other people, then obligation of type } 1 \mathrm{~A} \\
\text { is not fulfilled (you are still considered as hav- } \\
\text { ing committed violation of } 1 \mathrm{~A} \text { ) but even under } \\
\text { these circumstances an obligation of type } 1 \mathrm{C} \text { is } \\
\text { fulfilled. See the book Minhat Hinuch. }\end{array}$} \\
\hline
\end{tabular}

\section{Type 2. Full Prohibition}

The Bible forbids the eating of pork.

$F_{T}$ (eating pork), and we do not have $O_{T}(\neg$ eat pork). 
Leviticus 11:7-8

And the pig, because it is parts the hoof and is cloven-footed but does not chew the cud, is unclean to you. You shall not eat any of their flesh, and you shall not touch their carcasses; they are unclean to you.

\section{Type 3. Strong Obligation/Prohibition}

This has the structure

$$
O_{T} \neg X \wedge F_{T} X
$$

An example of this is the Biblical obligation/prohibition about work on the Sabbath (seventh day). We have, for $X=$ doing work, an obligation not to do work and also a prohibition on working. So this is a very strong demand from God!

Another example, if you have a house with accessible roof you must install a railing to the roof to prevent people falling off the roof. This can be interpreted as a typical safety rule. Its status is that of a weak obligation introduced for good practice. If you obey it, you will earn the good will of God. There is also prohibition on being without a railing. So if you do not obey it, there is no punishment. We formalise this by writing

$$
O_{T} \text { Rail and } F_{T} \neg \text { Rail. }
$$

To quote the Bible:

Deuteronomy 22:8

When you build a new house, you must build a railing around the edge of its flat roof. That way you will not be considered guilty of murder if someone falls from the roof.

Note that in the Sabbath example the Obligation is on lack of action and the prohibition is on action and in the roof example the obligation is on action and the prohibition is on lack of action.

\section{Contrary to Duties}

\section{Type CTD I. Obligation with Positive Contrary to Duty}

You should not steal and if you steal you should return what is stolen. We can write:

1. $F_{T} S$

2. $\quad\left(S \rightarrow O_{T} R\right)$

or maybe the dyadic formalisation:

2a. $\quad S \rightarrow O_{T}(R / S)$ 


\section{Type CTD II. Temporal Chain of CTDs}

This example is from the Bible.

1. You should not rape a woman.

2. If you do rape a woman you must marry her 3

3. If you marry the woman you raped you can never divorce her.

We write this as

$$
F_{T} R \wedge\left(R \rightarrow O_{T}(M / R)\right) \wedge\left(R \wedge M \rightarrow F_{T}(D / R \wedge M)\right)
$$

To quote the Bible:

Deuteronomy 22:28-29

If a man happens to meet a virgin who is not pledged to be married and rapes her and they are discovered, he shall pay the girl's father fifty shekels of silver. He must marry the girl, for he has violated her. He can never divorce her as long as he lives.

\section{Type CTD III. Fine Tuning Required}

Let us give some more examples of Contrary to Duties from the Talmud. These examples require further fine tuning and their delicate formalisation is postponed.

1. This is the mainstream example we mentioned before, which we recall here for comparison, that we should not steal but if we do steal we have an obligation to return the stolen property to its rightful owner. (This is a 'repairing' CTD.)

2. We have an obligation to pray three times a day. A morning prayer, an afternoon prayer and an evening prayer. The time for the afternoon prayer is from noon to sunset. The evening prayer should be done after sunset but before sunrise. The rules governing this are as follows:

(a) It is obligatory to pray the afternoon prayer between noon and sunset.

(b) If one was not able, due to circumstances beyond his control, to offer the afternoon prayer before sunset one can still fulfill the obligation by offering the afternoon prayer 13 minutes after sunset. (This is called 'make up'.)

(c) If time has passed and no afternoon prayer was offered then one can offer the evening prayer twice, to make up for the afternoon prayer.

3. Another example is the Yevama example. If a woman becomes a widow without children and her deceased husband has an unmarried brother, then the brother has a duty to marry the widow to continue the family line. If the brother does not want to do that, he has the duty to give the widow a special 'divorce' document to enable her to be free to marry. (This is a 'way out', it is not a CTD or a 'making up'.)

\footnotetext{
${ }^{3}$ Assuming she is not married. If she is married, the guy is in really serious trouble! If she is not married but does not want to marry the guy, he has to pay compensation only.
} 
4. A fourth example is the reading of the Book of Esther during the Purim festival. The obligation is to read it standing, not sitting. This is the a priori obligation. But if the reading was done sitting down, it does a posteriori discharge the reader from his obligation. The Talmud makes a distinction between our obligations before the event ('Lechatchila') and what is required after the event ('Bede'eved').

5. There are many more cases, for example where the same action violates several prohibitions and obligations, some of them contradictory. These are solved in practice (see Section 3).

Remark 1. The prayer examples and the Yevama example, are very interesting. They hint to a type of contrary to duties which fulfill the original obligation and are not necessarily just secondary obligations, which kick into action when the original obligation is violated. The CTD can actually cancel the original violation. It is not a disjunction. We do not have the disjunctive option of either reading the Book of Esther standing or sitting. We should a priori try to read it standing but if we read it sitting the original obligation to read it sitting is discharged. In comparison, if I steal a book and then return it, I am still in violation of the 'do not steal' obligation. The difference is whether the obligation relates to the process or to the resulting state (after the process).

\section{Discussion and Future Research}

In this section we discuss some issues to be clarified and pursued in future research.

The perceptive reader might wonder what kind of (Talmudic) logic we have here. We do have the ordinary deontic logic SDL for the operators $\left\{O_{D}, F_{D}\right\}$ and we have two new completely unrelated Talmudic modalities $O_{T}$ and $F_{T}$. We also have lots of examples for them. So where is the logic?

Our answer to this is threefold:

1. Consider a modal logic with three separate KD modalities generated by $O_{T}, F_{T}$ and $O_{D}$ and study the correct axioms governing them.

2. We can equivalently regard $O_{T} X$ and $F_{T} X$ not as modalities but as labels. So each wff $X$ will have several possible labels.

(a) neither $O_{T} X$ nor $F_{T} \neg X$

(b) $O_{T} X$ only

(c) $F_{T} \neg X$ only

(d) both $O_{T} X$ and $F_{T} \neg X$

So the logic would be standard deontic logic applied to labelled formulas. This approach also goes well with the fact that $O_{T}$ and $F_{T}$ obligation and prohibition carry reward or punishment for obeyance and violations respectively. So the labels can be used to indicate that information as well. Modal systems with labels exist in the literature primarily as Gentzen or tableaux systems and there is work by D. Gabbay and others in this direction [56]. So it should not be difficult to tailor a suitable Talmudic labelled variant of SDL. Our guess is that the system should also be intuitionistic, as we have already mentioned earlier. Let us leave this question to future research. 
3. The third remark about the logic involved is the nature of the CTDs in the Talmud. There should be more empahsis on resolving conflicting obligations and prohibitions. The system is built for people to use and live by day-by-day. So the most important feature of the logic is to resolve conflicting obligations and prohibitions arising from a multitude of CTD all triggered by past actions. For this again we need a labelled system. Let us give a modern example to show what we mean and thus realise that ordinary deontic logic has not fully addressed such problems.

Example 3. Suppose our starting point is that we have the following:

1. There should be no fence.

2. There should be no dog

3. If there is a dog there should be a fence

4. If there is a fence it should be white

5. If there is a dog and a fence it should be high

6. If there is a fence and it is not white it should be low

Some stubborn rebellious landlord does the following sequence of actions

(s1) get a dog

(s2) build a fence

(s3) paint the fence green.

He now decides to be a good boy and asks for our recommendation. Should he make the fence high or low? How do we proceed?

First let us label his actions by the violations he performed, and ask at each stage what our recommendation would have been. Then we ask if there is a simple case of reverse actions (e.g. get rid of the dog) which will restore consistency. Then we decide what to recommend.

So this is a special case of controlled revision see [7/8] 4

So to sum up, we probably need to extend SDL by allowing labelled formula and include a revision operator $* A$ ( $A$ revised) in the object language.

${ }^{4}$ The following is the labelled history of actions violations. "+" means obeyance, “-” means violation.

(s1) label $[(-b)]$

(s2) label $[(-b),(+c),(-a)]$

(s3) label $[(-b),(+c),(-a),(-d)]$.

If he makes the fence low we will get also $(+f)$ and $(-e)$, and if he makes the fence high we will also have $(-f)$ and $(+e)$.

On the basis of the above history of labels we make a decision.

Controlled revision applies when we start with a theory $\Delta_{0}$ and have a series of inputs $A_{1}, A_{2}, A_{3} \ldots$. At stage $n$ we have $\Delta_{n}$, and when we revise to accommodate $A_{n+1}$ we must remember the entire history of revisions and revise accordingly.

So, for example, if $\Delta_{0}=\{A, A \rightarrow B\}$ and we get $\neg B$, we revise and get $\Delta_{1}=\{\neg B, A \rightarrow B\}$. If we now get input $B$, we ordinarily may revise and get $\Delta_{2}=\{B, A \rightarrow B\}$. But in controlled revision we remember the history, so we know that we took out $A$ and hence we bring it back and revise to $\Delta_{2}^{\text {controlled }}=\{A, A \rightarrow B\}$. 
The reader should be aware that the Talmudic way of resolving conflict is different and new to the traditional methods. So there is novelty in that.

Note that Talmudic CTDs have special features as discussed in Remark 1 We can write $O X$ and the contrary to duty saying that if in practice you have done $X^{\prime}$ then we consider $O X$ as having been obeyed. So we can write $O X$ and $\neg X \rightarrow O X^{\prime}$ and if $X^{\prime}$ then there is no violation of $O X$.

Example 4. To give you a glimpse of Talmudic style conflict resolution consider the following two obligations

1. you should always be seen wearing a black suit at official receptions

2. you must always wear a dark blue dinner suit at evening formal dinners.

You get a conflict when invited to an evening do with Her Majesty The Queen. What to wear black or dark blue? Modern non monotonic logic will say rule 2 is more specific, so it has priority. Talmudic reasoning also accepts that the more specific norm may have priority, but in this case we have another simple option: Talmudic style conflict resolution will say that in the evening in electric light dark blue looks black. So there is no conflict! Note that this is not a logical solution but a practical one.

Note that we can give a practical solution to Example3 by recommending a low fence. Since the fence is painted green, it blends with the grass and plants and can be considered as not violating the obligation that there should be no fence, but only in this case!

\section{Acknowledgements}

We are grateful to the Deon 2010 referees for valuable comments.

\section{References}

1. Prakken, H., Sergot, M.: Contrary to duty obligations. Studia Logica 57(1), 91-115 (1996)

2. Prakken, H., Sergot, M.: Dyadic deontic logic and contrary to duty obligations. In: Nute, D. (ed.) Defeasible Deontic Logic. Synthese Library, vol. 263, pp. 223-262. Kluwer, Dordrecht (1997)

3. Gabbay, D.: Reactive Kripke semantics and contrary to duties. To appear in Journal of Applied Logic. Special issue on DEON 2008 (2011)

4. Gabbay, D.: Reactive Standard Deontic Logic, draft (February 2010)

5. Gabbay, D.: Labelled Deductive Systems. Oxford University Press, Oxford (1996)

6. Basin, D., D’ Agostino, M., Gabbay, D., Matthews, S., Vigano, L. (eds.): Labelled Deduction. Springer, Heidelberg (2000)

7. Gabbay, D., Pigozzi, G., Woods, J.: Controlled Revision - An Algorithmic Approach for Belief Revision. Journal of Logic and Computation 13(1), 15-35 (2003)

8. Gabbay, D., Rodrigues, O., Russo, A.: Revision Acceptability and Context. Springer, Heidelberg (2010) 